\author{
Military Technical College \\ Kobry El-Kobbah, \\ Cairo, Egypt.
}

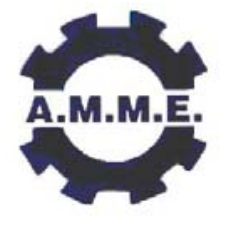

$13^{\text {th }}$ International Conference on Applied Mechanics and Mechanical Engineering.

\title{
EVALUATION OF WHEELED VEHICLE MOBILITY AND PERFORMANCE PREDICTION ON DEFORMABLE SOIL
}

\author{
RAGHEB $^{* *}$ H., HEGAZY** S. and GIRGIS** N.
}

\begin{abstract}
Mobility is the ability to move freely and rapidly over the terrain of interest to accomplish varied combat objectives. The vehicle weight and its footprint determine the resultant ground pressure that the vehicle imparts on the soil. The soil strength, coupled with the ground pressure, determines vehicle cone index, $\mathrm{VCl}$, which is the key for vehicle mobility. This paper presented a theoretical evaluation of the vehicle mobility and predicts its performance on deformable soil. For this purpose, soil field test was carried out using cone penetrometer in situ to measure the strength of different soils. The vehicle cone index was calculated using vehicle parameters. A comparison of rating cone index with the vehicle cone index indicates whether the vehicle can negotiate the given soil condition for a given number of passes.
\end{abstract}

\section{KEY WORDS}

Vehicle mobility, Soil testing, Vehicle performance, cone penetrometer

\section{NOMENCLATURE}

b Tire width, $\mathrm{m}$

CI Cone index, $\mathrm{N} / \mathrm{m}^{2}$

$\mathrm{d} \quad$ Tire diameter, $\mathrm{m}$

$f \quad$ Factor depending on axle load

MI Mobility Index

$\mathrm{n} \quad$ Number of axles

RCI Rating Cone Index

RI Remolding Index

$\mathrm{VCI}_{1}$ One-pass Vehicle Cone Index

$\mathrm{VCI}_{50}$ 50-pass Vehicle Cone Index

** Egyptian Armed Forces. 


\author{
W Vehicle weight \\ $\bar{X} \quad$ Axle weight factor \\ $\bar{Y} \quad$ Weight factor
}

\title{
INTRODUCTION
}

Vehicle mobility is the overall capability of a vehicle to move from place to place while retaining its ability to perform its primary mission [1]. Terrain trafficability means the ability of terrain to support the passage of vehicles [1]. There are a lot of studies and articles in existence that deal with components related to tractability. Hintze [2], Rounsevell [3] and Earl [4] have set out to predict soil strength with the aid of climatic data. Davis and Laut [5], Saarilahti [6] have estimated the terrain trafficability and soil strength. Birkel [7] took into account the interaction between the terrain and the vehicle. Orava [8] used raster analysis to determine terrain trafficability as needed for planning military activities, but his application included only terrain parameters and did not contain the attributes of the vehicle, and therefore it could not be used to solve routing problems.

The mobility of a vehicle is influenced by three main parameters; vehicle parameters, soil parameters and environmental parameters (Climate conditions and driver's skill). The vehicle parameters; vehicle performance, geometric configuration, vehicle construction and economy of operation have considerable influence on vehicle mobility [9]. The soil parameters affecting vehicle mobility include; behavior under loading, transient and permanent parameters [10-12].

B. Maclaurin [14] compared the available models for predicting the tractive performance of wheeled and tracked vehicles on soft cohesive soils. The author found that there is a major limitation in the development of a reliable empirically vehicle model due to the lack of reliable experimental data, especially in the low traction region. A. Bodin [15] described a tracked vehicle for use in studying the influence of different vehicle parameters on mobility on soft terrain. The author found that the nominal ground pressure has a significant effect on the tractive performance of tracked vehicle. When the nominal ground pressure is increased, the drawbar pull coefficient was decreased.

Jody et al [10] explained how $\mathrm{VCl}$ is measured, and compared with different methods of predicting $\mathrm{VCl}$ for one-pass performance of wheeled vehicles in fat clay soils. It is further clarified that MMP (mean maximum pressure) should not be compared with $\mathrm{VCl}$. They modified and developed existing relationships for using MMP to predict $\mathrm{VCl}_{1}$ for wheeled vehicles in clay. Therefore the resulting relationships allow comparison between MMP and $\mathrm{MI}$ in terms of their ability to predict $\mathrm{VCl}$. A vehicle cone index is obtained using vehicle parameters. A comparison of the $\mathrm{VCl}$ and the soil $\mathrm{RCl}$ will result in a prediction of whether the vehicle is mobile or not (GO/NO GO) in a particular soil.

\section{EVALUATION OF SOIL STRENGTH FOR TRAFFICABILITY}

The evaluation of soil strength for vehicle mobility is obtained in the field using plate 
sinkage test or Cohron shear graph test or cone penetrometer test. The cone penetrometer is a simple instrument designed to give a quick and easily obtained index of soil strength [13]. The soil-trafficability test set include cone penetrometer, soil sampler, and remolding equipment as shown in Fig. 1 The cone penetrometer set consists of the following items:

- A 30-degree cone with a 0.5 inch2 $(325 \mathrm{~mm} 2)$ base area.

- A steel shaft $485 \mathrm{~mm}$ long and $10 \mathrm{~mm}$ diameter.

- Proving ring with dial range from 0-150 Lb or from 0-300 Lb/inch2 (0 - 2.07 $\mathrm{N} / \mathrm{mm} 2$ ).

- Micrometers dial.

- A handle.

The cone was pressed into the soil at a uniform speed, $30 \mathrm{~mm} / \mathrm{sec}$ (approximately 15 seconds in soft soil) and the force required to press the cone through the soil layers was indicated on the dial inside the proving ring in the penetrometer handle. The pressure corresponding to this force was an index of the soil resistance and was called the soil cone index. An assistant should be provided to record the readings taken by the operator. The operator will quickly learn to shift his vision from the rod at the ground to the dial at the proper moment, meanwhile maintaining a constant penetration rate. Five to seven penetrations should be performed to get a good statistical average and an estimate of the variability of the terrain with depth. In this research, the soil strength was measured at different depths as clarified in Table (1) and plotted in Fig. 2, the average $\mathrm{Cl}$ was calculated. In case of fine-grained soil, a remolding test was used to obtain rating cone index, which was the response to repetitive loads. In this case a sample from the critical layer was ejected into the remolding cylinder and pushed to its bottom with the foot of the drop-hammer shaft. While the cone penetrates the soil sample, the $\mathrm{Cl}$ readings were recorded for the successive depths of the cone.

Table (1): Soil situ testing

\begin{tabular}{|c|c|c|}
\hline Depth, in & Cone index, Lb/in ${ }^{2}$ & \multirow{2}{*}{ Average Cl } \\
\hline 1 & 22 & \multirow{2}{*}{86.5} \\
\hline 2 & 30 & \\
\hline 3 & 105 & \\
\hline 4 & 130 & \\
\hline 5 & 125 & \\
\hline 6 & 107 & \\
\hline
\end{tabular}

\section{EVALUATION OF VEHICLE MOBILITY}

For evaluating Ml for wheeled vehicles there are many empirical relationships, some formulae neglect the ground clearance, power/weight ratio and transmission [10]. The vehicle mobility for three vehicles (Gaz 69, Hummer M998 and Zil 131) was calculated using series of equations developed by waterways experiment station, WES [15-17] known as the "Mobility Index". The mobility index is expressed in terms of vehicle parameters; tire load and dimensions, engine and transmission characteristics. The 
parameters required for mobility evaluation are shown in Table (3). The Mobility Index, Ml for all wheel drive vehicle was calculated from equation (1). For a not all-wheel drive vehicle, the MI was computed according to the formula for all wheel drive vehicles, and then multiplied by 1.4. The output results for mobility index for the three vehicles are shown in Tables (4-6).

$M I=\left(\frac{\text { Contact } \text { Pr essure Factor } \times \text { Weight Factor }}{\text { Tire Factor } \times \text { Grouser Factor }}+\right.$ Wheel Load Factor - Clearance Factor $)$ $\times$ Engine Factor $\times$ Transmission Factor

where:

Contact pressure Factor $=\frac{\text { Gross Weight, Lb }}{\text { Nominal Tyre Width, in } . \times \text { Outside Radius, in } . \times \text { No. Of Tyres }}$

Weight Factor, $\bar{Y}$ was calculated according to the weight range, as shown in Table (2).

Table (2): Weight Factor

\begin{tabular}{|l|c|}
\hline Weight Range, $\mathrm{Lb}(\mathrm{KN})$ & Weight Factor Equation \\
\hline$<2000(8.9 \mathrm{KN})$ & $\bar{Y}=0.553 \bar{X}$ \\
\hline $2000-13,500(8.9-60 \mathrm{KN})$ & $\bar{Y}=0.033 \bar{X}+1.050$ \\
\hline $13,501-20,000(60-88.9 \mathrm{KN})$ & $\bar{Y}=0.142 \bar{X}-0.420$ \\
\hline$>20,000(88.9 \mathrm{KN})$ & $\bar{Y}=0.278 \bar{X}-3.115$ \\
\hline
\end{tabular}

where:

$$
\begin{aligned}
& \bar{X}=\frac{\text { Gross Weight }, \text { Lb }}{\text { No. Of Axles } \times 1000} \\
& \text { Tire Factor }=\frac{10+\text { Tire Width, in. }}{100}
\end{aligned}
$$

Wheel Load Factor $=\frac{\text { Gross Weight, Lb }}{\text { No. Of Axles } \times 2000}$

ClearanceFactor $=\frac{\text { Clearance, } \text { in } .}{10}$

Engine Factor: $\quad \geq 10 \mathrm{hp} /$ ton of vehicle weight $=1.00$

$<10 \mathrm{hp} /$ ton of vehicle weight $=1.05$

Transmission Factor: $\quad$ Automatic $=1.00$

Manual $=1.05$

Grouser Factor: With Chains $=1.05$

Without Chains $=1.00$ 
Based on the mobility index (MI), a parameter called the vehicle cone index ( $\mathrm{VCl}$ ) was calculated. The $\mathrm{VCl}$ represents the minimum strength of a soil in the critical layer that permits a given vehicle to successfully make a specific number of passes, usually one pass or 50 passes. For instance, the value of $\mathrm{VCl}$ for one pass and 50 passes, $\mathrm{VCl}_{1}$ and $\mathrm{VCl}_{50}$, was obtained either by equations (3-5) [18-19] or using graphs as shown in Fig. 3 [13]. The $\mathrm{Ml}$ above 40 , the $\mathrm{VCl}_{50}$ can be obtained from the equation (6) [10]. The evaluation of vehicle mobility module was shown in flow chart shown in Fig. (4)

For one pass, if $M I \leq 115$

$$
V C I_{1}=11.48+0.2 M I-\left(\frac{39.2}{M I+3.74}\right)
$$

And if $M I>115$

$$
V C I_{1}=4.1 \times M I^{0.446}
$$

And for 50 passes, for any MI value

$$
V C I_{50}=28.23+0.43 M I-\left(\frac{92.67}{M I+3.67}\right)
$$

And for $M I>40$

$$
\mathrm{VCI}_{50}=25.2+(0.454 \times M I) .
$$

\section{ANALYSES OF RESULTS}

Using Tables (2 through 4), a comparison between $\mathrm{VCl}_{1}, \mathrm{VCl}_{50}$ and $\mathrm{RCl}$ indicates whether the vehicles can Go / No Go on deformable soil. In the case of going, the performance prediction on deformable soil in terms of rolling resistance, and drawbar pull was investigated using module shown in Fig. (4). the required soil parameters for performance module are shown in Table (6). The drawbar pull of the three tested vehicles is shown in Figs. $(5-6)$ on sand and loam. From these figures as the wheel slip increase the drawbar pull increase until it reaches the maximum value corresponding to complete wheel slip. Also these figures display that the vehicle \# 2 gives the higher drawbar pull than the others. Therefore, the rolling resistance of the two other vehicles is lower than the vehicle \#2 as shown in Figs. (5 - 6) on sand and loam.

\section{CONCLUSIONS}

The vehicle mobility evaluations for three different vehicles were carried out and the performance of the tested vehicles in terms of drawbar pull and rolling resistance were predicted. The mobility evaluation was based on vehicle parameters and soil testing in situ, using cone penetrometer. Because the readings must be taken in about 15 seconds with constant penetration rate according to user manual for soft soil, this needs an assistant to record the readings and shift his vision from the rod at the ground to the dial at the proper moment. Therefore, an error with recording the results was anticipated. A good measuring of soil strength using digital electronic cone penetrometer gives accurate results for soil strength and so correct decision for going on deformable soil 


\section{REFERENCES}

[1] International society for terrain-vehicle systems STANDARDS, Journal of Terramechanics, 1977, Vol. 14, No. 3, pp. 153 to 182.

[2] Hintze, D. 1990. The prediction of soil strength with the aid of climatic data. In: ISTVSEur 5. p. 17-24.

[3] Rounsevell MDA. A review of soil workability models and their limitations in temperate regions. Soil Use Manag 1993;9 (1):15-21.

[4] Earl R. Prediction of trafficability and workability from soil moisture. Soil Tillge Res 1997; 40:155-68.

[5] Davis JR, Laut P. An expert system to estimate trafficability in a remote region in of Australia. Al Appl 1989;3 (1):17-26.

[6] Saarilahti M. Ecomodel. In: Haarlaa R, Salo J, editors, University of Helsinki. Publication 31, February 2003; 2002. Available from:

http://ethesis.helsinki../julkaisut/maa/mvaro/publications/31/programs/

[7] Birkel PA. Terrain trafficability in modelling and simulation. Technical paper SEDRIS; 2003. Available from: http://www.sedris.org/pr11trpl.htm, 2003-9-11.

[8] Orava E. Maastoanalyysi ,Terrain Analysis for Military Purpose.,1999

[9] Emad Sayed Anbar, "Technical Evaluation of off-road Vehicle Mobility", MSC thesis, Military Technical College, Cairo, 1993.

[10] Jody D. Priddy *, William E. Willoughby, "Clarification of vehicle cone index with reference to mean maximum pressure", Journal of Terramechanics 43 (2006) 85-96

[11] Planning and design of roads, airfields, and heliports in the theater of operations, Soils Trafficability, www.globalsecurity.org/military/library

[12] Bolezlay Henzelka, "Theory of Wheeled Vehicles-Part II", Printed Lectures, Bartos, CSSR, Nov. 1964.

[13] H. Ragheb, "Prediction of off road vehicle mobility", MSC thesis, Military Technical College, Cairo, 2007

[14] B. Maclaurin, "Comparing the NRMM (VCI), MMP and VLCl traction models", Journal of Terramechanics 44 (2007) 43-51

[15] A. Bodin, "Development of a tracked vehicle to study the influence of vehicle parameters on tractive performance in soft terrain", Journal of Terramechanics 36 (1999) 167-181 
[16] K.J. Melzer, "Possibilities of Evaluating The Traction of Tires for Off-Road Transportation Vehicles", Journal of Terramechanics, Vol. 21, No. 4, pp 309-333, 1984.

[17] I-S Ageiking, "Off-The-Road Mobility of Automobiles", Translated From Russian by Admrind Publishing Co, New Delhi, 1987.

[18] Gamal E.H. Okeil, "The proper Approach for Comparing Military Vehicles and Evaluation Tests For Determining The Suitability of Service In The Armed Forces", Research Paper, Vehicle Department, A.F, 1981.

[19] Nabil Elhosseiny, A. Nagib, Samir Eldessouki and Raafat Masrouga, "Scientific Approach For Comparing Vehicles and Their Technical Evaluation" Research Paper, Vehicle Department, A.F, 1986.

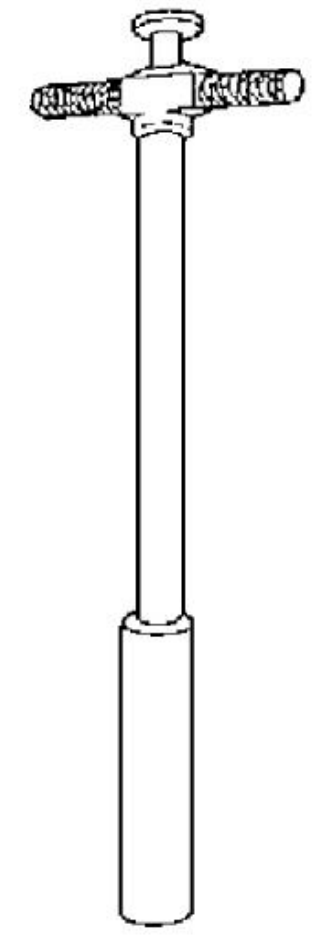

Hammer

Base
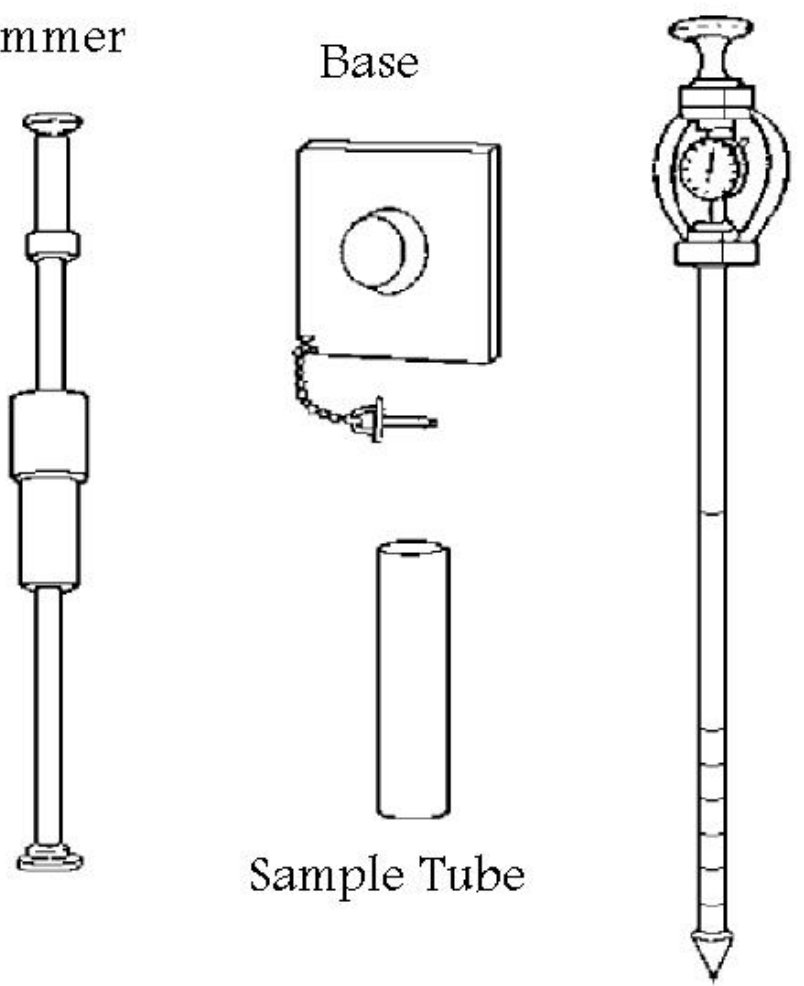

Sampler

Remolding Equipment

Cone Penetrometer

Fig. (1): The soil-trafficability test set [13] 


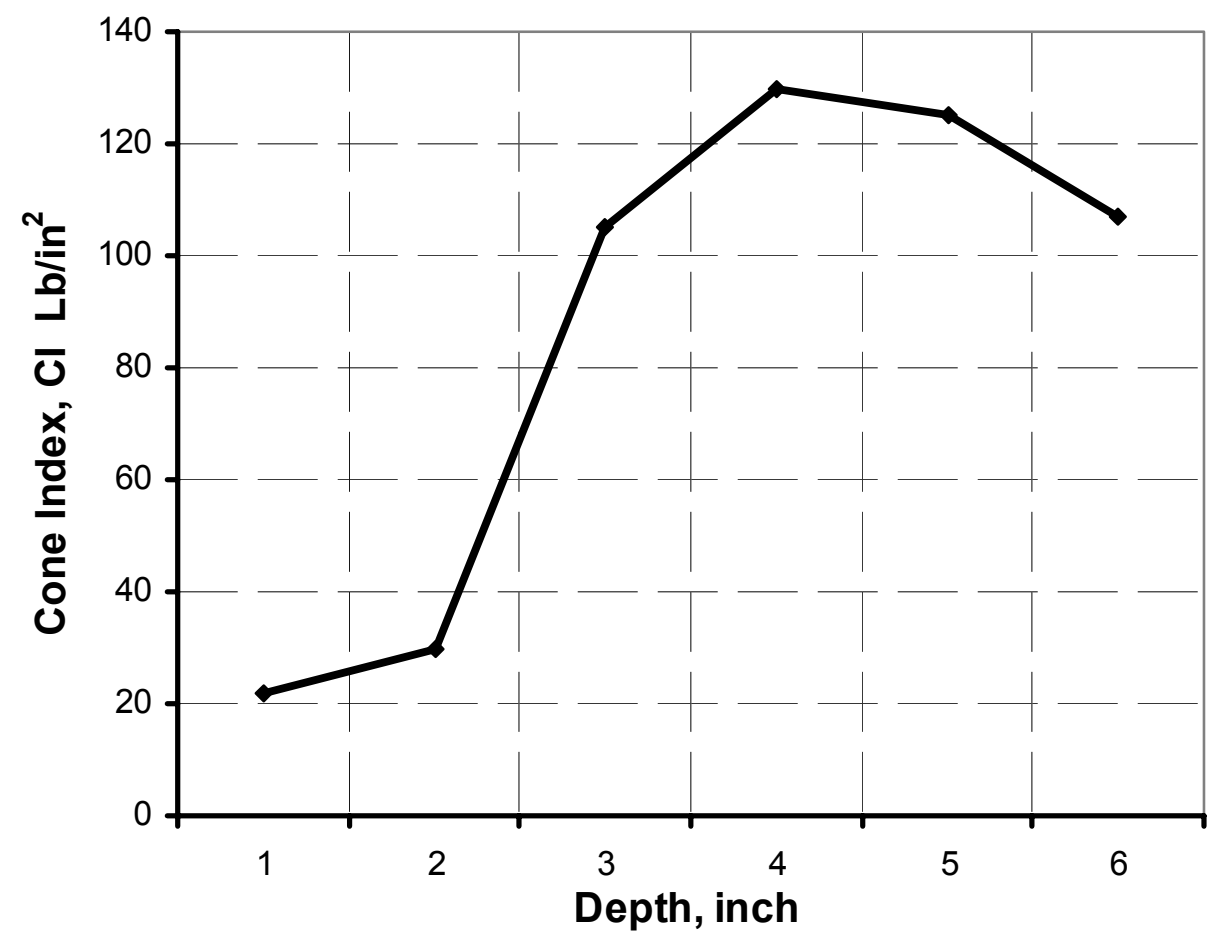

Fig. (2): Variation of soil strength with depth

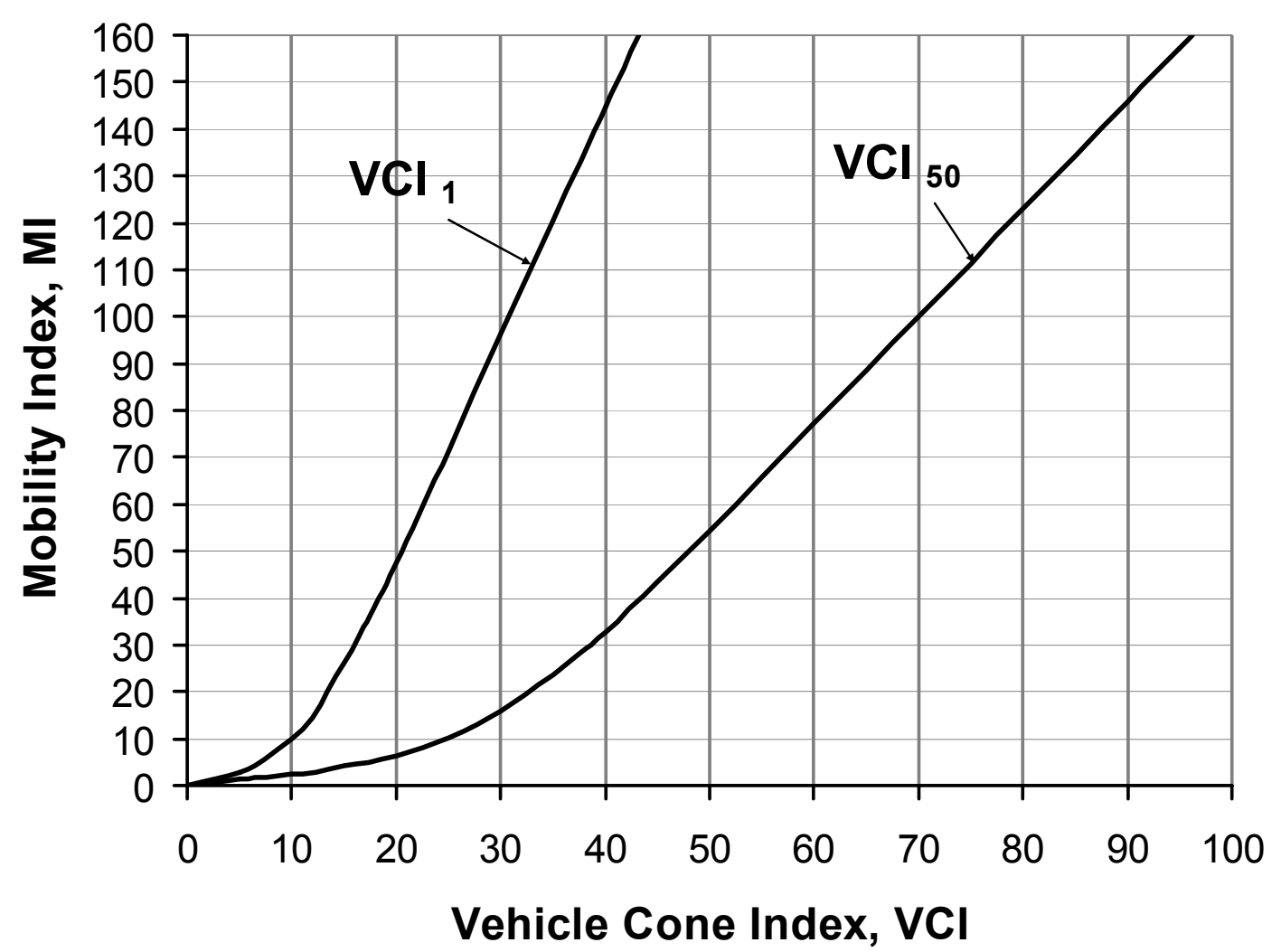

Fig. (3): Estimated relation of $\mathrm{MI}$ to $\mathrm{VCl}$ [13] 
a) Vehicle mobility GO/NO GO module.

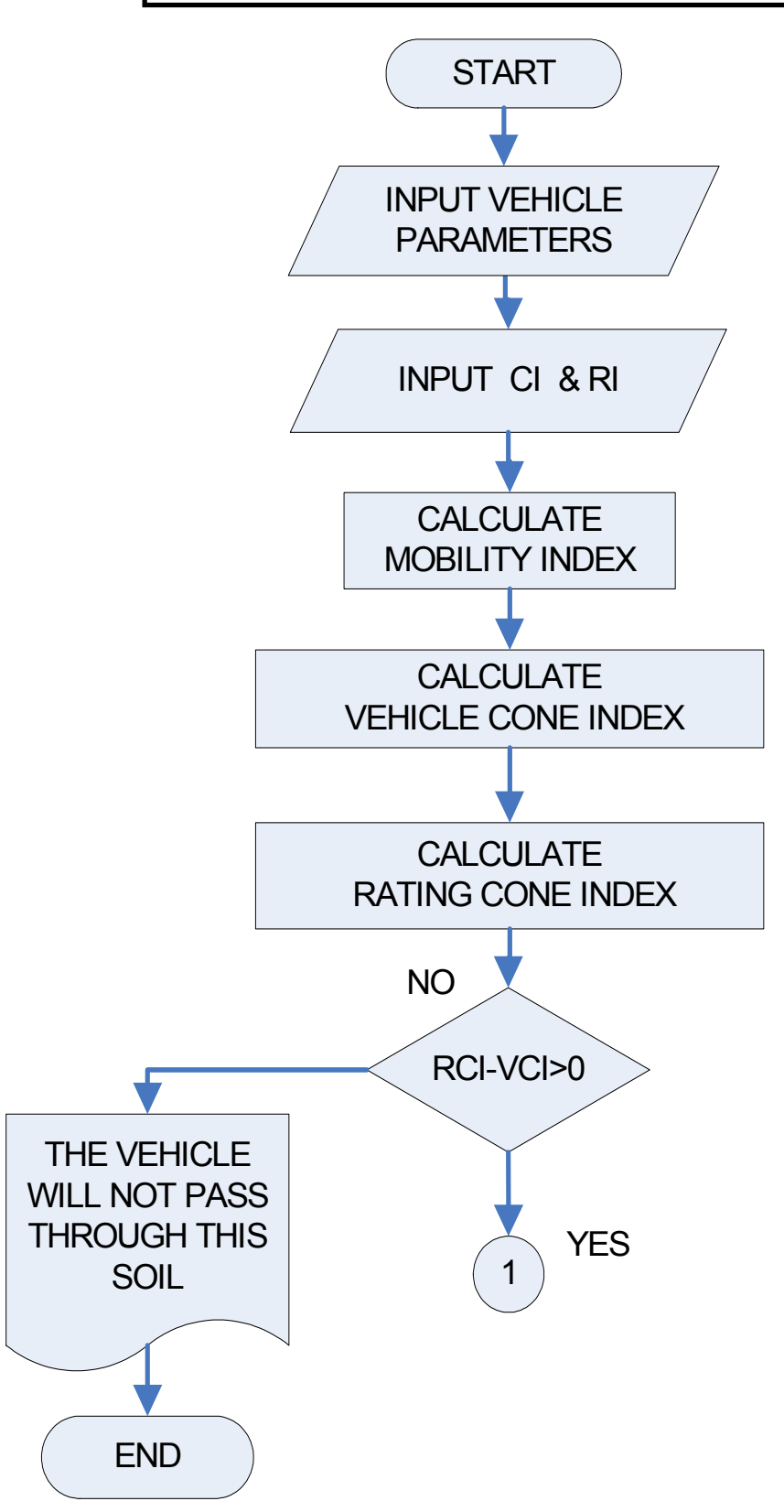

b) Performance prediction module.

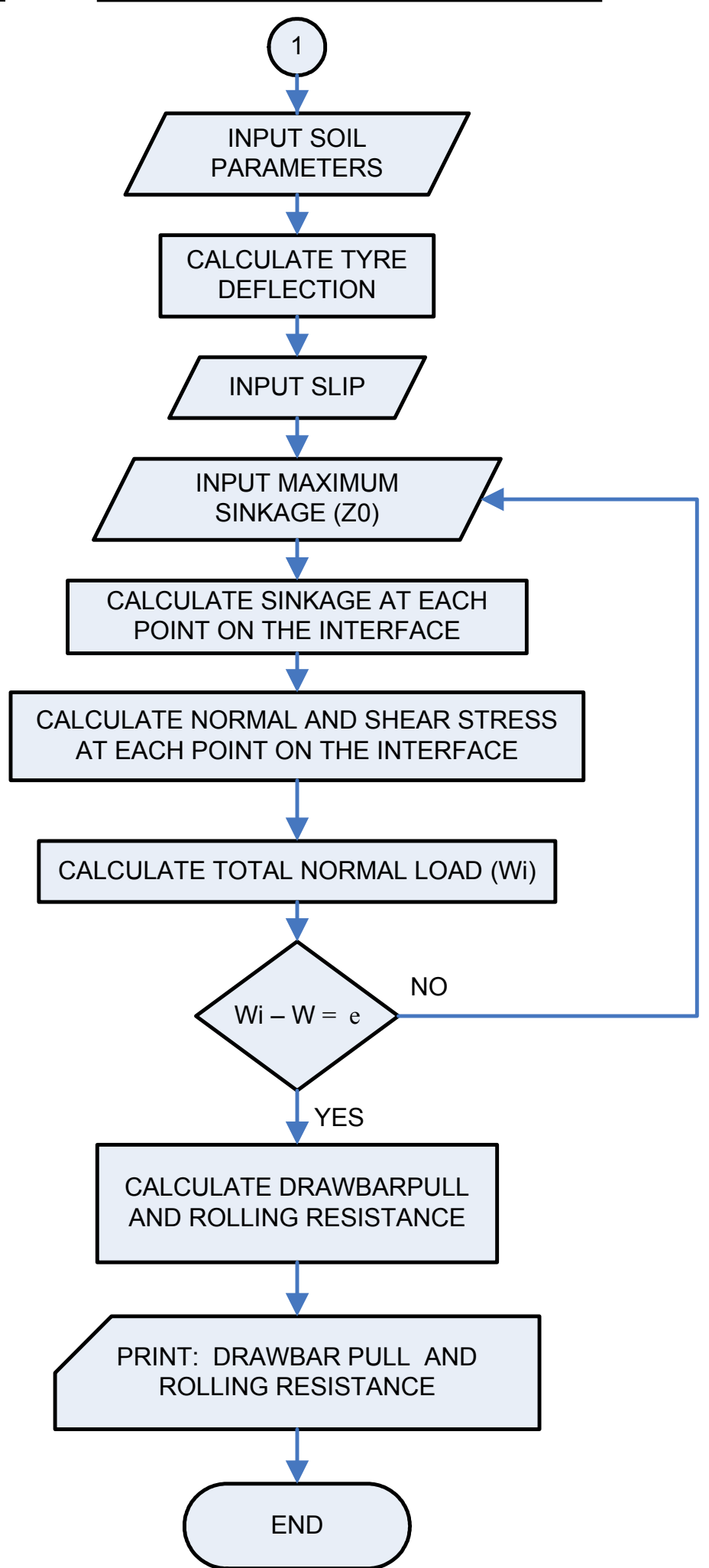

Fig. (4): Flow chart of the computer program 


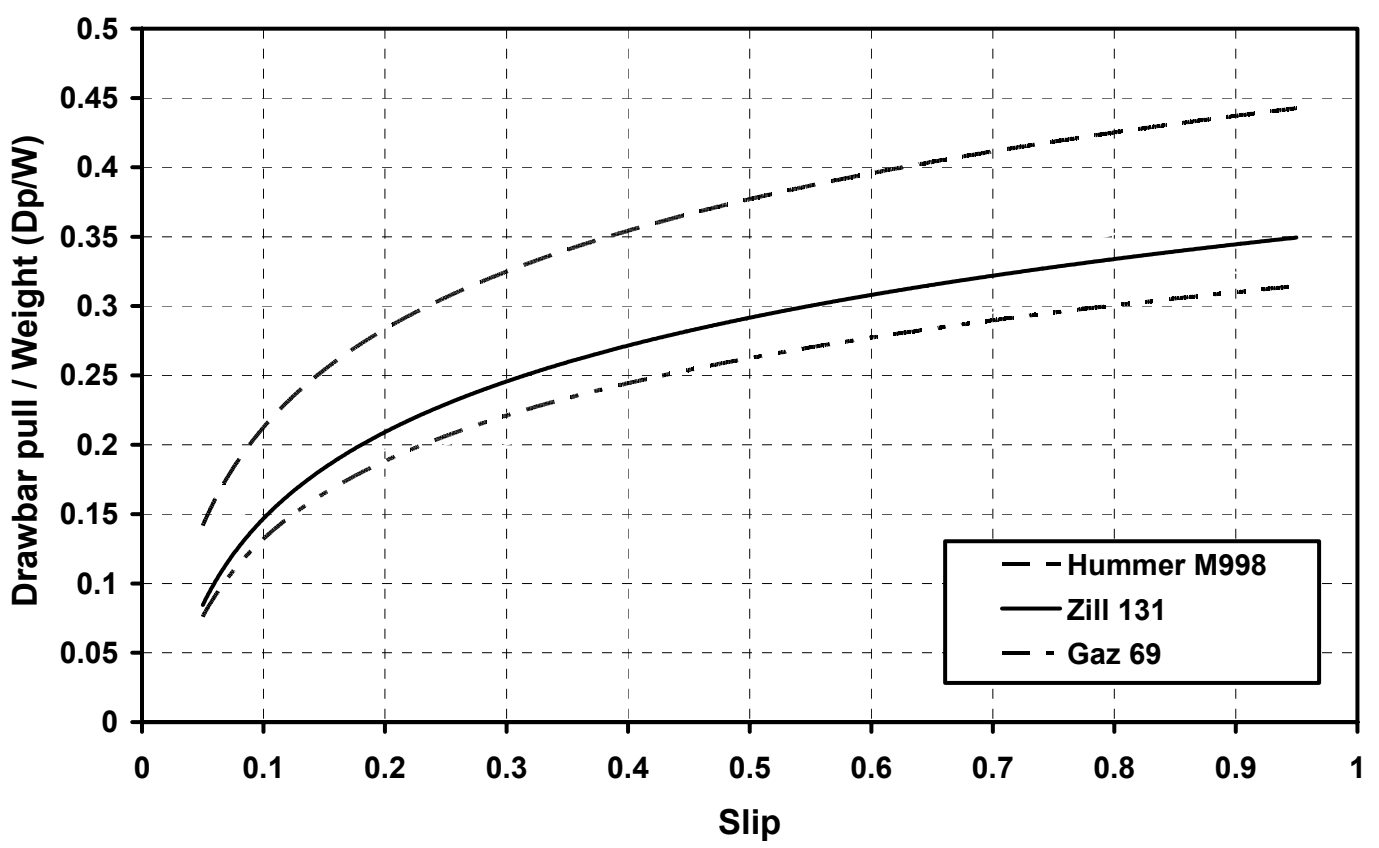

Fig. (5): Drawbar pull / Weight Vs. slip for sand

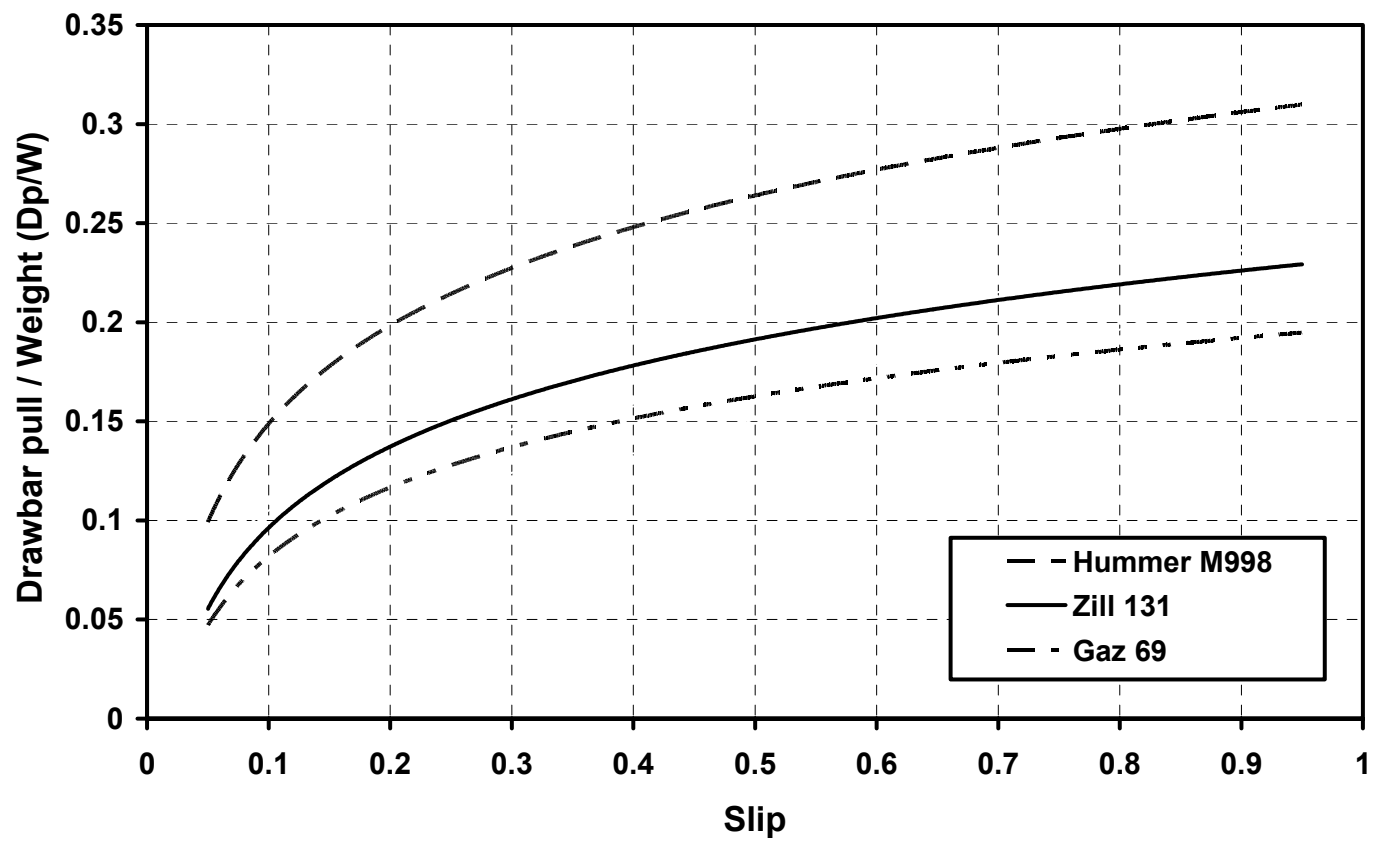

Fig. (6): Drawbar pull / Weight Vs. slip for loam 


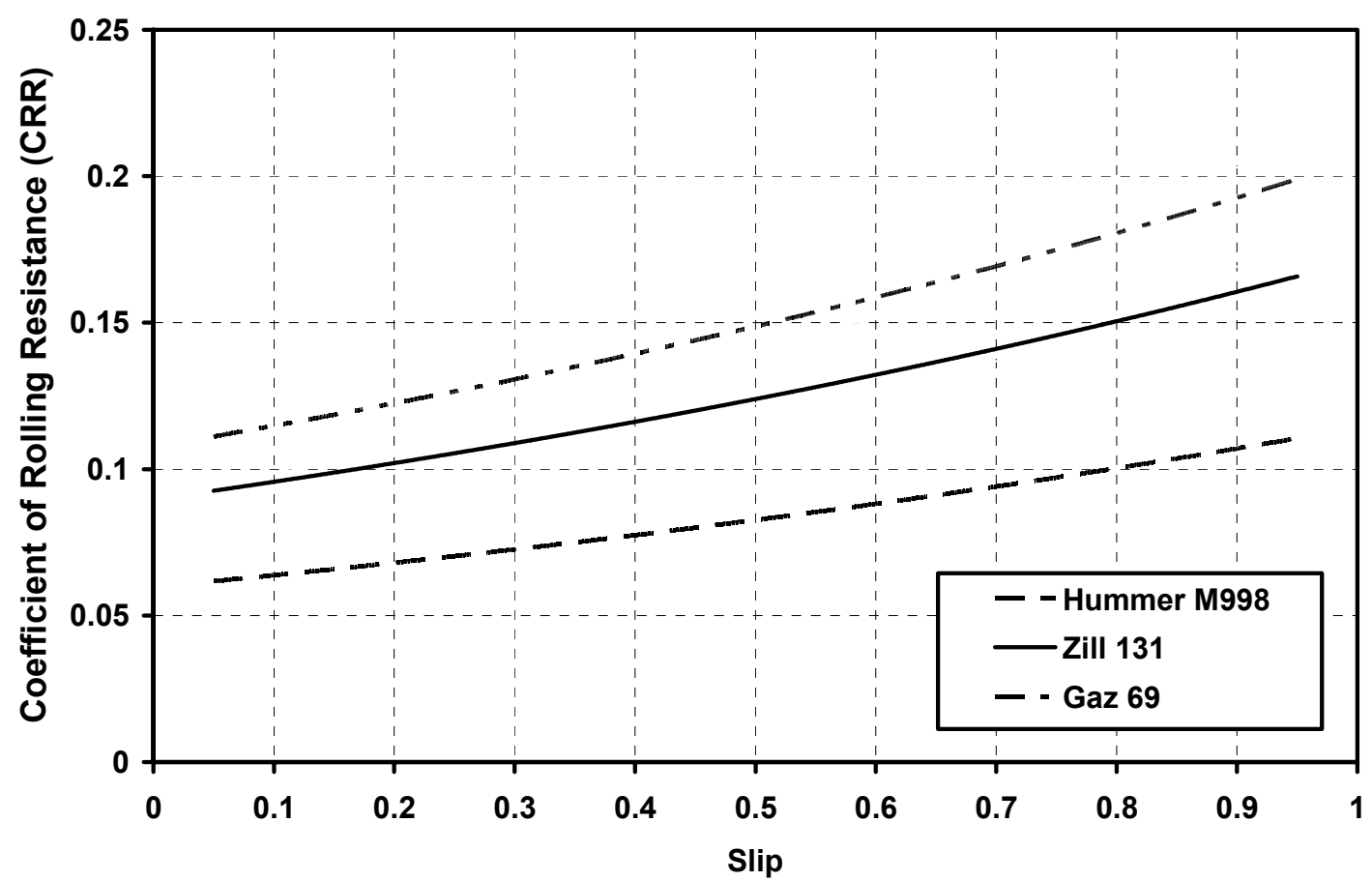

Fig. (7): Coefficient of rolling resistance Vs. slip for sand

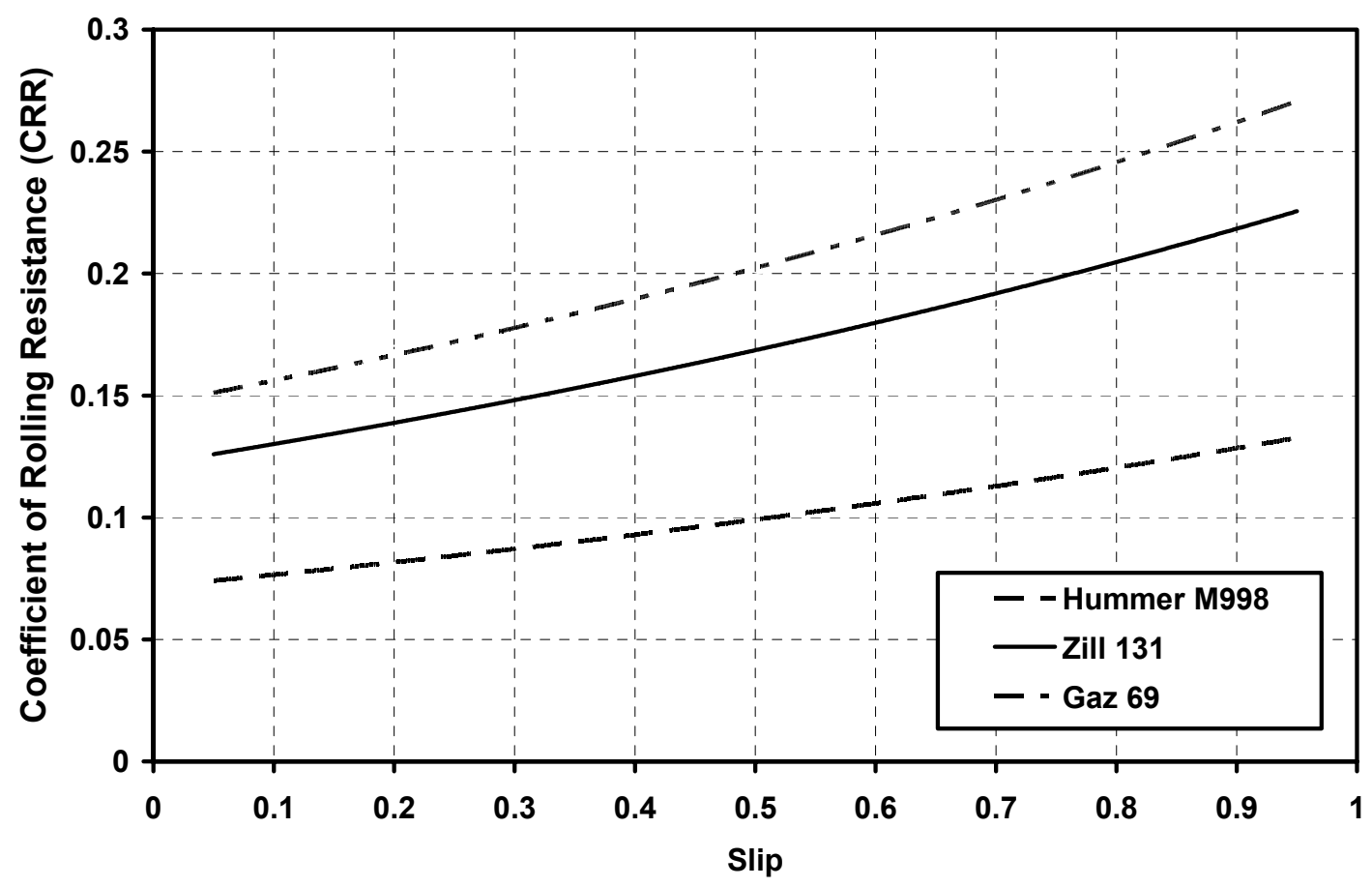

Fig. (8): Coefficient of rolling resistance Vs. slip loam 
Table (3): Vehicle parameters required for calculating mobility index

\begin{tabular}{||l|l|l|l||}
\hline \hline Parameter & $\begin{array}{l}\text { vehicle \# 1 } \\
\text { (Gaz 69) }\end{array}$ & $\begin{array}{l}\text { vehicle \# 2 } \\
\text { (Hummer M998) }\end{array}$ & $\begin{array}{l}\text { vehicle \# 3 } \\
\text { (Zil 131) }\end{array}$ \\
\hline Specific power: (hp/Ton) & 26 & 43 & 13.5 \\
\hline Vehicle weight: Lb $(\mathrm{kN})$ & 21 & 35 & 111 \\
\hline Tire diameter: in $(\mathrm{m})$ & 0.6534 & 0.8952 & 0.9656 \\
\hline Tire width: in $(\mathrm{m})$ & 0.1650 & 0.3175 & 0.3050 \\
\hline Ground clearance: in $(\mathrm{m})$ & 0.21 & 0.41 & 0.38 \\
\hline No. of tires. & 4 & 4 & 6 \\
\hline No. of axles. & 2 & 2 & 3 \\
\hline Contact pressure factor & 8.709 & 10.86 & 12.15 \\
\hline Weight factor & 1.128 & 1.178 & 0.4147 \\
\hline Tire factor & 0.165 & 0.1839 & 0.2201 \\
\hline Wheel load factor & 1.18 & 1.938 & 6.348 \\
\hline Clearance factor & 0.7874 & 0.8661 & 1.417 \\
\hline Transmission type & Manual & Manual & Manual \\
\hline Grouser Factor & Without chains & Without chains & Without chains \\
\hline \hline
\end{tabular}

Table (4): output results for vehicle \# 1, Gaz 69

\begin{tabular}{|l|l|l|l|}
\hline Output parameter & Loam & Sand & Clay \\
\hline Mobility index, MI & 101 & 101 & 101 \\
\hline CI & 27.18 & 52.36 & 86.5 \\
\hline VCI $_{1}$ & 35.32 & 35.32 & 35.32 \\
\hline VCI $_{50}$ & 70.21 & 70.21 & 70.21 \\
\hline RI & 0.80 & 0.85 & 1 \\
\hline RCI & 21.7 & 44.5 & 86.5 \\
\hline
\end{tabular}

Table (5): output results for vehicle \# 2, Hummer M998

\begin{tabular}{||l|l|l|l|}
\hline Output parameter & Loam & Sand & Clay \\
\hline Mobility index, MI & 50 & 50 & 50 \\
\hline CI & 27.18 & 52.36 & 86.5 \\
\hline VCI $_{1}$ & 18.5 & 18.5 & 18.5 \\
\hline VCI $_{50}$ & 43 & 43 & 43 \\
\hline RI & 0.80 & 0.85 & 1 \\
\hline RCI & 21.7 & 44.5 & 86.5 \\
\hline
\end{tabular}


Table (6) output results for vehicle \# 3, Zil 131

\begin{tabular}{|l|l|l|l|}
\hline Output parameter & Loam & Sand & Clay \\
\hline Mobility index, MI & 90.4 & 90.4 & 90.4 \\
\hline CI & 27.18 & 52.36 & 86.5 \\
\hline VCI $_{1}$ & 32.22 & 32.22 & 32.22 \\
\hline VCI $_{50}$ & 67.1 & 67.1 & 67.1 \\
\hline RI & 0.80 & 0.85 & 1 \\
\hline RCI & 21.7 & 44.5 & 86.5 \\
\hline
\end{tabular}

Table (7) Soil parameters required for the model

\begin{tabular}{|l|l|l|l|l|l|l||}
\hline Soil type & $\mathrm{K}_{\mathrm{c}}\left(\mathrm{kN} / \mathrm{m}^{\mathrm{n}+1}\right)$ & $\mathrm{K}_{\varphi}\left(\mathrm{kN} / \mathrm{m}^{\mathrm{n}+2}\right)$ & $\mathrm{C}(\mathrm{kpa}))$ & $\Phi($ degree $)$ & $\mathrm{K}(\mathrm{mm})$ & $\mathrm{n}$ \\
\hline Loam & 33.5 & 615 & 7.5 & $37^{\circ}$ & 25 & 0.75 \\
\hline Sand & 30 & 500 & 10 & 30 & 25 & 0.55 \\
\hline Clay & 27.5 & 175 & 15 & 29 & 19 & 0.388 \\
\hline
\end{tabular}

